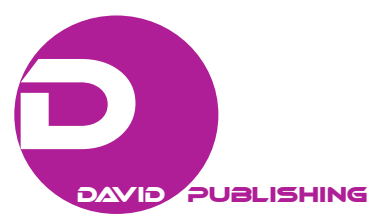

\title{
Kanban System Design for Hospital Pharmacy - Case study
}

\author{
Mitka Eleftheria \\ Kimmeria Campus, Xanthi, 67100, Greece
}

\begin{abstract}
This is a brief overview of principles, views and methods, of the Kanban system for the pharmacy of a general hospital. The main goal is the reduction of stores managed by the pharmacy, as well as improvement of the mode of operation. Solutions to problems, such as inadequate storage space, delay in serving patients or clinics and the expiration of various pharmaceutical formulations, stored for so long time, are provided. The philosophy behind the Kanban procurement system and specifically its applicability to a pharmacy underperforming in terms of efficiency, in Greece, are described. Based on the analysis of stock requirement, item stock prices and demand, it is concluded that a significant percentage of the stocked drugs can be procured using the Kanban System. Significant cost savings and operational advantages following the Kanban System will take place. The challenging endeavor is the analysis, design and application of a system that supports the proposed procurement method. Hospital pharmacies in Greece and in other countries that face an economic crisis may largely benefit after using the Kanban System. Moreover, the system is applied on a hospital pharmacy of a 250 bed Greek General Hospital estimating a monetary annual benefit about $50 \%$ lower overall cost for medicines and consumable health material.
\end{abstract}

Keywords: Lean management, Hospital Pharmacy, Kanban System, Value, ABC_XYZ analysis, waste, continuous improvement

\section{Introduction}

Hospital is a complex intricate organization comprises providers, therapies, physical location, technology and innovation that require continuous improvement towards providing what patient wants quickly, efficiently, and with little waste. The complex procedures of a Greek General Hospital is the objective of this paper focusing on the application of lean management systematically in the hospital pharmacy, as Lean Hospital is considered a common practice in health care organizations in USA and other countries ("qualitysafety," 2015). Observing the activities that take place on the value stream of processes, identifying the root causes of the non-value adding activities such as tremendous allocation of resources (people, technology, shared information), overworked staff, inefficient processes and bad service, the health care organization lead to a lean topos health provider (Tsigkas and Freund, 2008).

The hospital that was studied was accused for over budgeted costs for medications during 2013 since Greece is facing economic crisis and it is characterized as red hospital of Greek health care system that need help from Hellenic republic, government and Ministry of Health. The director of hospital pharmacy has to report and explain to the Greek authorities for the over budgeting spent for medications in year 2013. The goal of this study was the application of Kanban System estimating Kanban quantities and reallocating the budget

Ph.D Candidate, Department of Electrical and Computer Engineering, Democritus University of Thrace. E-mail: em3933@ee.duth.gr 
cost for medications and consumable health material efficiently enough to overcome the deficit. This system helps in achieving a stable working environment in the battlefield of competitiveness at the lower overall cost while the Lean Hospital has the best chances to win the battle of surviving, making strategic inventory management a reality.

\section{Review of Lean Management}

The paper highlights the adapting of Toyota Production System (TPS) idea to healthcare delivery services. The principles of this system contribute with concept, technology solutions and processes that lead to produce cars with low cost, best quality, short lead time and elimination of waste (Tsigkas, 2005). The lean management is synonymous to TPS since it uses less of everything (effort, parts, space, time, equipment) compared to other manufacturing production systems adding value from the customer's point of view. Value is considered any specifications and procedures of production system that the end consumer is ready to pay for. Waste or muda is the non-adding value activities or services that do not add value to customer's experience, is anything other than using minimum resources for achieving higher efficiency and accelerating momentum (Toyota Manufacturing Kentucky, 2003, The Toyota production system, 2009) and do not contribute directly to the society.

The lean management was the development of scientific management that was first best evidenced from Frederick Winslow Taylor and Henry Ford (Holweg, 2007). During 1940, Taiichi Ohnov (Ohno, 1998) identifies that defects of production system in automobile manufacturing was the result of stock on hand that lead to dead costly capital, increased storage space and defective products. Toyota Motor Corporation achieved long-term success, after decades, undergoing continuous iterative learning circles that serve as foundation of development. The overall goal was adding value to the end-product and elimination of all forms of waste that was based on Plan-Do-Check-Act circles of W. Edwards Deming with its roots in lean thinking to pursue perfection (Deming, 1986).

\section{Kanban System design for a hospital pharmacy}

The Kanban system provides a systematic way based on $\mathrm{ABC}-\mathrm{XYZ}$ analysis of stock requirement, item stock prices and demand, proving that a significant percentage of the stocked drugs can be procured as it aligns the patient's demand with supply chain and attacking inventory issues. It seems the only strategy, by all accounts, for this Greek general hospital that is fraught with problems and lack of sustainability under the current circumstances of economic crisis.

\section{ABC-XYZ Analysis}

According to $\mathrm{ABC}-\mathrm{XYZ}$ analysis, inventory levels will be accurately calculated based on Kanban codes of medicine and health material while afterwards Kanban quantity is calculated based on the analysis of stock requirement, item stock prices and demand. The medicines' codes used by the pharmacy were segmented and prioritized in different segments were 835 and consumable health materials were 401 . The analysis was applied separately for medicines and consumable health material. The medicines were divided in 3 categories. The codes classified " $\mathrm{A}$ " are expensive (represent $5-10 \%$ of the codes that correspond to $60-80 \%$ of the overall inventory), B includes less expensive (represent $10-30 \%$ of codes that correspond to $10-30 \%$ of the overall inventory) and on $\mathrm{C}$ are the cheapest ones (represent $60-85 \%$ of codes that correspond to remaining $5-15 \%$ of the overall inventory). X classifies medicines with high/stable demand, $\mathrm{Y}$ mediocre while on $\mathrm{Z}$ the low demand. 
The codes included in $\mathrm{X}$ with big $\mathrm{X}$ are suitable for Kanban while as $\mathrm{X}$ getting smaller, the kanban ability decreases (Figure 1). The medicines of AZ are not suitable for Kanban. There exist codes that pharmacist have to decide whether to include them or no in kanban system.

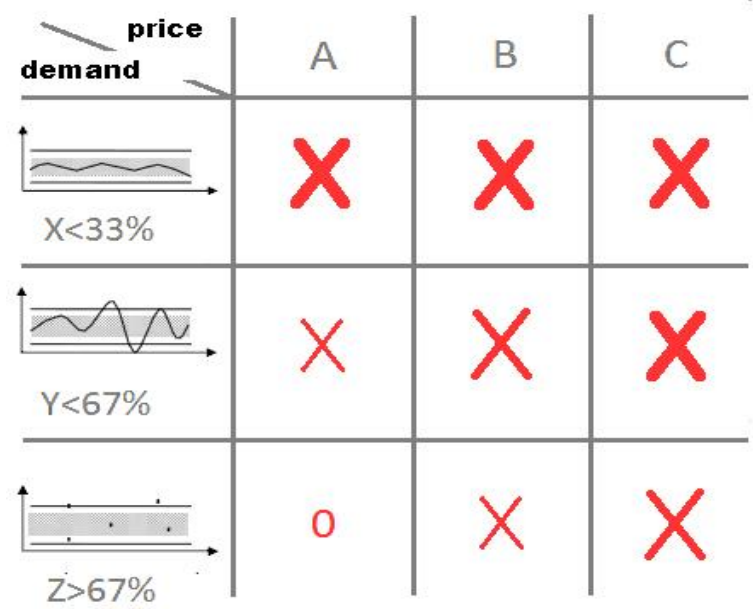

Figure 1. ABY-XYZ analysis.

\section{Strategic Inventory Management-Systems Approach}

Many organizations apply the $\mathrm{ABC}-\mathrm{XYZ}$ analysis in order to prioritize the levels of inventory. After the level of inventory is defined, they can optimally allocate their resources. Therefore, the companies set goals according to the segments such as policy in entitlement time in 2 days for " $\mathrm{A}$ " codes. One of the biggest advantages of this method is that is easily understood and establish a control mechanism for the control of inventory levels over the segments and the strategy is shown in Table 1 that propose the management for every code and the replenishment time according to volatility. By comparing the replenishment time with inventory on hand, pharmacist can quickly identify which codes are over entitlement that leads to excessive inventory and which are under entitlement that result in stock out.

Table 1

ABC classification

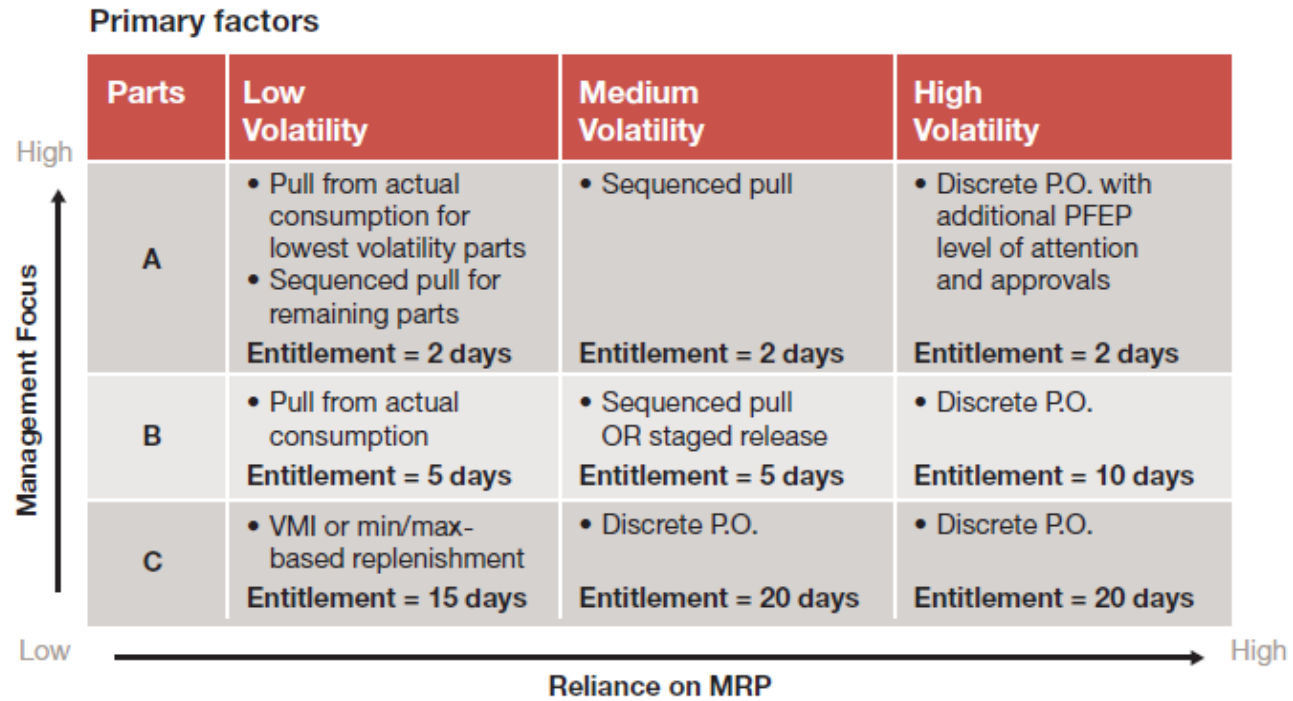




\section{Calculating the Kanban Quantity}

Comparing the results of ABC-XYZ analysis, the author reaches the conclusion that $46,9 \%$ of medication codes that are managed by the pharmacy can be included in the Kanban System while the 53,1\% are unsuitable (Table 2).

The General Hospital - Case Study

People's health is directly connected with the use and development of the medicines. In order to investigate thoroughly the design of a kanban system, a 250 bed General Hospital in Greece was studied. True data information from the hospital was used that contained the actual consumption of medications and consumable goods within the year 2013. The General Hospital that was studied has 3 sectors: Medical, Nursing and Administration. Taking account the staff data, it is calculated that planned permanent posts are 542, the covered posts are 343 while the empty are 199 (Diagram 1). So the hospital in order to complete its staff should employ 542 overall employers in the 3 sectors while now has 343 .

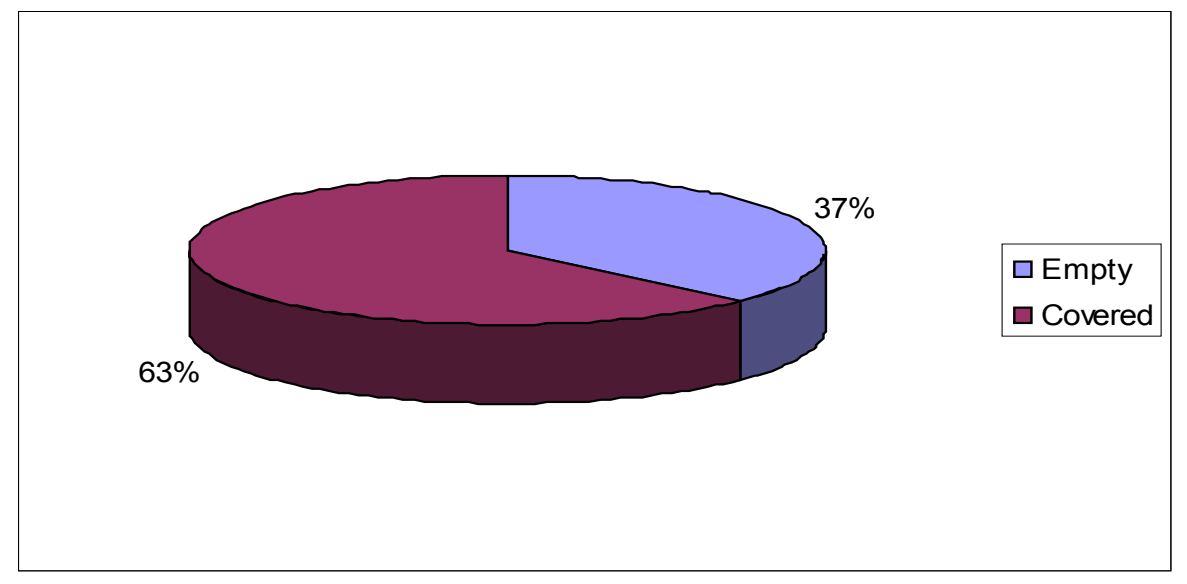

Diagram 1. Empty and covered posts according staff data.

In medical sector, the planned permanent posts are 93 while the covered are 73 . In nursing, there exist 241 planned permanent posts while the covered are 165. In administration, the planned permanent posts are 34 while the covered are 27.

Based on the data $\mathrm{ABC}-\mathrm{XYZ}$ analysis was applied as a lean management technique and the conclusions that came out are summarized in Tables 2 and 3.

According to the Inventory Entitlement Model, Strategic Inventory Management was applied in order to calculate the Kanban quantity $(\mathrm{Kq})$ required in the replenishment time that solve the $80 \%$ of inventory management problems using (1.1) and Table 2:

$$
K_{q}=\frac{D_{c} \times Q \times R}{H \times P}
$$

Dc: Medicine designed daily rate at capacity

Q: Quantity used per medicine code for product

$\mathrm{R}$ : Replenishment time for the medicine

H: Time available for medicine replenishment

$\mathrm{P}$ : Medicine package size 
Table 2

The results of ABC-XYZ analysis based on the data for consumption of medications during 2013 (Mitka, 2015)

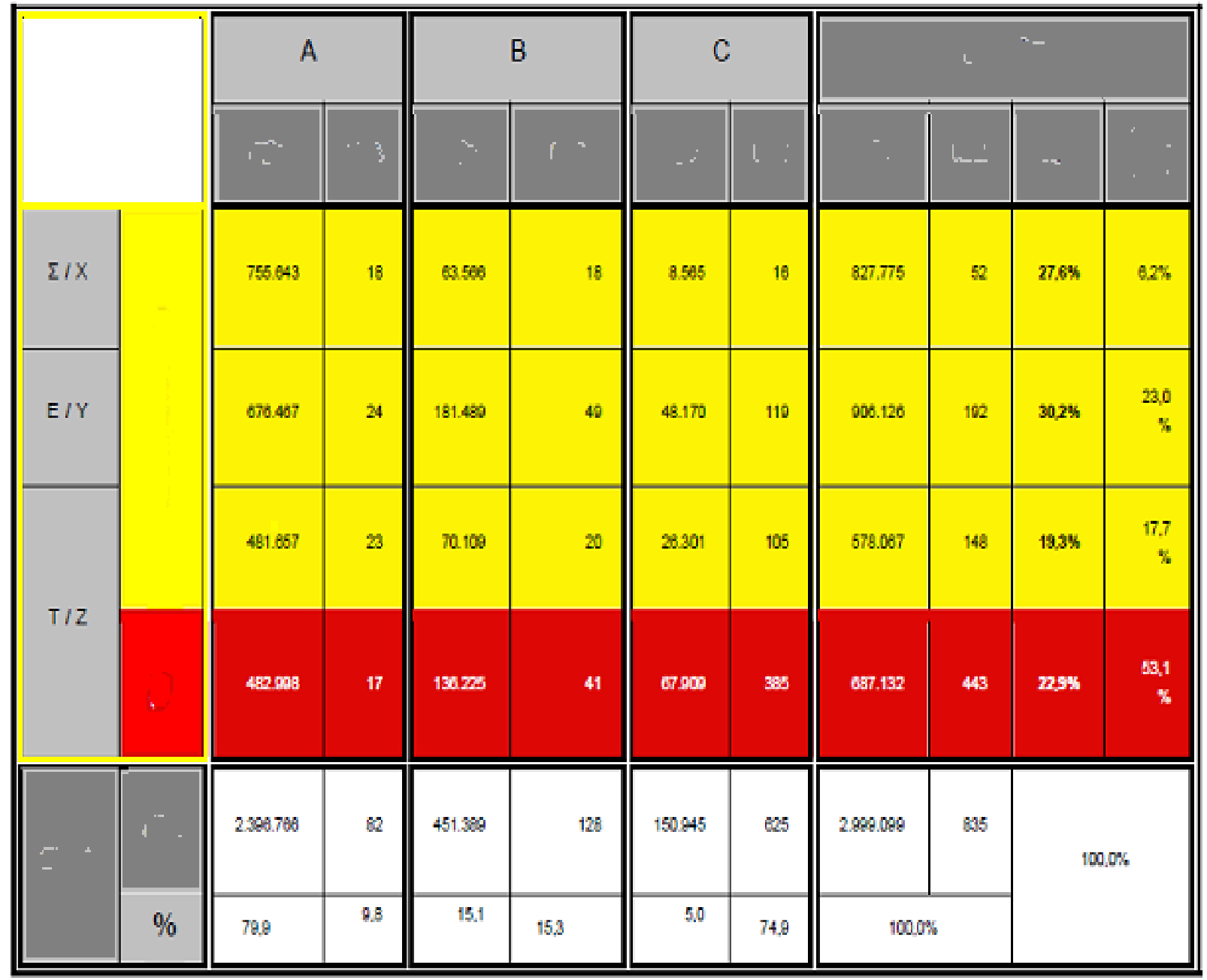

Furthermore, the results for category 'AX' of medication codes using as example the medicine RINGER LACTATE/BIOEEP 1000ML BOTTLE++ with daily rate at capacity 1 piece and average price $1,11 €$ are the following:

Dc: daily rate at capacity 1 piece

Q: Quantity used per medicine code is 1

R: Replenishment time for the medicine 2 days or 48 hours

$\mathrm{H}$ : Time available for medicine replenishment is 8 hours

S: 1 shift per day in the pharmacy

$\mathrm{P}$ : Medicine package size $\mathrm{P}=1$.

$$
K_{q}=\frac{1 \times 1 \times 48}{8 \times 1 \times 1}=6
$$

The kanban quantity of RINGER LACTATE/BIOEEP 1000ML BOTTLE++ that should be contained in the inventory of the pharmacy in order to provide high quality healthcare services for 2 days (Table 1) is 6 pieces. 
In category 'AY' of medication codes using as example the medicine ZINACEF DRPDINJ $750 \mathrm{MG} / \mathrm{VIAL}+$ with daily rate at capacity 8 pieces and average price $1,01 €$ using the following:

Dc: daily rate at capacity 8 pieces

Q: Quantity used per medicine code is 1

$\mathrm{R}$ : Replenishment time for the medicine 2 days or 48 hours

$\mathrm{H}$ : Time available for medicine replenishment is 8 hours

S: 1 shift per day in the pharmacy

$\mathrm{P}$ : Medicine package size $\mathrm{P}=1$.

$$
K_{q}=\frac{8 \times 1 \times 48}{8 \times 1 \times 1}=48
$$

Table 3

The results of $A B C-X Y Z$ analysis based on the data for consumption of consumable health material during 2013, (Mitka, 2015)

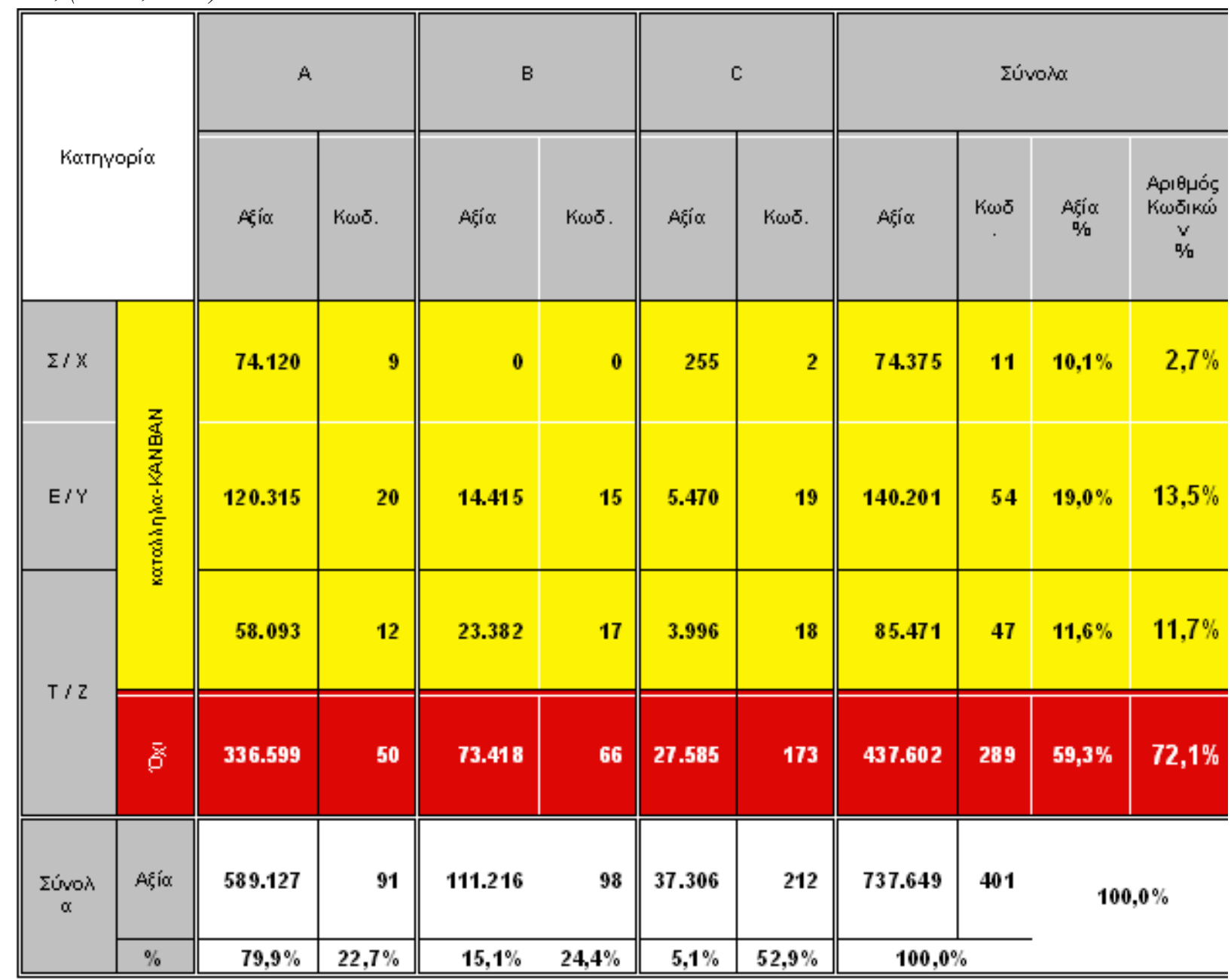

The kanban quantity of ZINACEF DRPDINJ 750MG/VIAL+ that should be contained in the inventory of the pharmacy in order to provide high quality healthcare services for 2 days (Table 1) is 48 pieces.

In category 'AZ1' of medication codes using as example the medicine INNOHEP INJSOL 10X4500 
IU/0,45XI + with daily rate at capacity 3 pieces and average price $2,71 €$ taking account the following:

Dc: daily rate at capacity 3 pieces

Q: Quantity used per medicine code is 1

$\mathrm{R}$ : Replenishment time for the medicine 2 days or 48 hours

$\mathrm{H}$ : Time available for medicine replenishment is 8 hours

S: 1 shift per day in the pharmacy

$\mathrm{P}$ : Medicine package size $\mathrm{P}=1$.

$$
K_{q}=\frac{3 \times 1 \times 48}{8 \times 1 \times 1}=18
$$

The kanban quantity of INNOHEP INJSOL $10 \mathrm{X} 4500 \mathrm{IU} / 0,45 \mathrm{XI}+$ that should be contained in the inventory of the pharmacy in order to provide high quality healthcare services for 2 days (Table 1 ) is 18 pieces.

In category ' $\mathrm{BX}$ 'of medication codes using as example the medicine GREPID F.C. TAB 75MG/TAB $\mathrm{BTx} 30$ BLISTERS (PVC/PE/PVDC/ALU) with daily rate at capacity 16 pieces and average price $0,52 €$ using (1.1):

$$
K_{q}=\frac{16 \times 1 \times 120}{8 \times 1 \times 1}=240
$$

The kanban quantity of GREPID F.C. TAB 75MG/TAB BTx30 BLISTERS (PVC/PE/PVDC/ALU) that should be contained in the inventory of the pharmacy in order to provide high quality healthcare services for 5 days (Table 1) is 240 pieces.

In category ' $\mathrm{BY}$ ' of medication codes using as example the medicine SODIUM CHLORIDE $0.9 \%$ INJSOINF 50ML BAG BAXTER with daily rate at capacity 15 pieces and average price $0,67 €$ using (1.1):

$$
K_{q}=\frac{15 \times 1 \times 120}{8 \times 1 \times 1}=225
$$

The kanban quantity of SODIUM CHLORIDE 0.9\% INJSOINF 50ML BAG BAXTER that should be contained in the inventory of the pharmacy in order to provide high quality healthcare services for 5 days (Table 1) is 225 pieces.

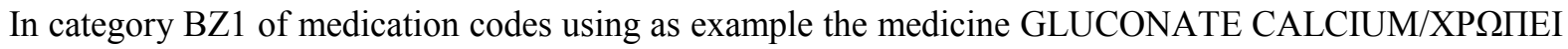
INJSOL 5\% 10ML AMP+ with daily rate at capacity 1 piece and average price $0,87 €$ using the following:

Dc: daily rate at capacity 1 piece

Q: Quantity used per medicine code is 1

R: Replenishment time for the medicine 10 days or 240 hours

$\mathrm{H}$ : Time available for medicine replenishment is 8 hours

S: 1 shift per day in the pharmacy

$\mathrm{P}$ : Medicine package size $\mathrm{P}=1$.

$$
K_{q}=\frac{1 \times 1 \times 240}{8 \times 1 \times 1}=30
$$

The kanban quantity of GLUCONATE CALCIUM/XPSПEI INJSOL 5\% 10ML AMP+ that should be contained in the inventory of the pharmacy in order to provide high quality healthcare services for 10 days (Table 1) is 30 pieces.

In category ' $\mathrm{CX}$ ' of medication codes using as example the medicine PRIMPERANINJSOL $6 \mathrm{X} 10 \mathrm{MG} / 2 \mathrm{MLAMP}+$ with daily rate at capacity 13 pieces and average price $0,13 €$ using (1.1): 


$$
K_{q}=\frac{31 \times 1 \times 360}{8 \times 1 \times 1}=1395
$$

The kanban quantity of PRIMPERANINJSOL 6X10MG/2MLAMP+ that should be contained in the inventory of the pharmacy in order to provide high quality healthcare services for 15 days (Table 1) is 1395 pieces.

In category ' $\mathrm{CY}$ ' of medication codes using as example the medicine ISOFREDILFC.TAB 400MG/TABBTx30 (BLIST $3 \times 10$ ) with daily rate at capacity 4 pieces and average price $0,87 €$ using (1.1):

$$
K_{q}=\frac{4 \times 1 \times 480}{8 \times 1 \times 1}=240
$$

The kanban quantity of ISOFREDILFC.TAB 400MG/TABBTx30 (BLIST 3x10) that should be contained in the inventory of the pharmacy in order to provide high quality healthcare services for 20 days (Table 1) is 240 pieces.

As far as category ' $\mathrm{CZ1}$ ' of medication codes, using as example the medicine RENAGEL CAPS $180 \mathrm{X} 800 \mathrm{MG} / \mathrm{CAP}+$ with daily rate at capacity 3 pieces and average price $0,7553 €$ and $(1.1)$ :

$$
K_{q}=\frac{3 \times 1 \times 480}{8 \times 1 \times 1}=180
$$

The kanban quantity of RENAGEL CAPS $180 \mathrm{X} 800 \mathrm{MG} / \mathrm{CAP}+$ that should be contained in the inventory of the pharmacy in order to provide high quality healthcare services for 20 days (Table 1) is 180 pieces.

According to Table 2 the total cost of medicine codes that are suitable for Kanban System are 2999099-687132=2311967€ taking account the Figure 1 .

\section{Results}

Applying the Kanban System indicates that for the medicine codes in category AX for 20 days the cost is calculated counting kanban quantity, cost of medicines, codes of 'AX', 10 days that is $6 * 1,11^{*} 18^{*} 10=1199 €$. With the same function for all categories and replenishment time respectively according to Figure 1 it is easy to estimate that for 20 days the total cost for category A: $23938 €$, B: $39997 €, C: 43080 €$ respectively. The total cost for 20 days for all categories is $\mathrm{A}+\mathrm{B}+\mathrm{C}=107015 €$. The total annual cost is estimated $107015 * 365 / 20=$ $1953024 €$. The monetary benefit is $2311967-1953024=358943 €$ that is approximately $20 \%$ lower cost.

Nevertheless, the cost for the consumable health material according to Table 3 for the same General Hospital for the codes suitable for Kanban System is estimated 737649 - $437602=300040 €$.

Applying the Kanban System indicates that for the health material codes classified in category 'AX' for 20 days the cost is calculated by counting kanban quantity, cost of health material, codes of 'AX', 10 that is $1686 * 0,04 * 9 * 10=6070 €$. With the same function for all categories and replenishment time respectively according to Figure 1, it is easy to estimate that for 20 days the total cost for category A: $6192 €, B: 2303 €$ and C: $335 €$ respectively. Total cost for 20 days for all segments is $\mathrm{A}+\mathrm{B}+\mathrm{C}=8830 €$. The annual total cost 8830 * $365 / 20=161148 €$. So monetary benefit is $300040-161148=138892 €$ that is approximately $50 \%$ lower cost.

\section{Discussion}

The application of lean principles can be achieved easily without additional resources and offers multiple benefits in a health organization such as a General Hospital. Summarizing the advantages of the pharmacy that applies Kanban system as the one was studied are the following: 
- Reducing overall costs of hospital

- Allocating resources and strategic management of inventory

- Reducing waste

- Quick and accurate service of patients

- Reducing needs of storage space for stock

- Reducing medications and health material stored but not used and must be disposed of

- Reducing waste of time due to ill-formed or deficient prescription or waiting for servicing in the pharmacy due to inventory in the floor

The author concludes that majority of pharmaceutical mistakes are caused by faulty conditions that lead people to make errors and not to prevent them. The Kanban system has the capacity to deal with wasteful steps and non-adding activities in sector of care processes in a number of dimensions namely medical assessment errors, wrong drugs, adverse drug reaction and mainly reduce of excess supply that leads to medications and health material stored but not used and must be disposed of, reducing additional costs. The commitment to kanban system culture, techniques and lean health care philosophy should start from the very top management of the organization. In other words, it should be a part of the organizational strategy to improve patient care that involves internal and external customers of the system such as patients, society, public and private insurers, ancillary support staff that provide clinical and non-clinical healthcare services and third parties in healthcare system and of course of authorities (Mitka, 2015).

\section{References}

Deming, E. (1986) Out of the crisis. Cambridge: Cambridge University Press.

Holweg, M. (2007) The genealogy of lean production. Journal of Operations Management, 25 (2): 420-437.

Ohno, T. (1998) Toyota Production System, beyond large scale production. Portland, Ed. OR: Productivity Press.

Toyota Manufacturing Kentucky, Inc. (2003) The Toyota production system.

Toyota Motor Corporation (2009) Toyota production system.

Tsigkas, A.C. and Freund. R. (2008) Part III, Value Chains. In: Tomasz Koch (ed) Lean business systems and beyond, IFIP international federation for information processing. Springer, Boston, MA, 257: 423-431.

Tsigkas, A.C. (2005) Mass customization through value adding communities. Presented at Third world wide conference on mass customization and personalization, Hong Kong.

http://qualitysafety.bmj.com/content/13/6/472.full [last accessed: 2014-27-5]

Mitka, E. (2015) Application of Kanban System on a hospital pharmacy. Hellenic journal of nuclear medicine 18 (suppl 3):4-10. 